\title{
Two-Phase Flow Mass Transfer Analysis of Airlift Pump for Aquaculture Applications
}

\author{
Rashal Abed ${ }^{1}$, Mohamed M. Hussein ${ }^{1}$, Wael H. Ahmed ${ }^{1, *}$ and Sherif Abdou ${ }^{2} \mathbb{D}$ \\ 1 School of Engineering, University of Guelph, Guelph, ON N1G 2W1, Canada; rabed@uoguelph.ca (R.A.); \\ husseinm@uoguelph.ca (M.M.H.) \\ 2 FloNergia Inc., Burlington, ON L7L 4Y3, Canada; sherif.abdou@flonergia.com \\ * Correspondence: ahmedw@uoguelph.ca; Tel.: +1-(519)-824-4120 (ext. 53674)
}

check for updates

Citation: Abed, R.; Hussein, M.M.; Ahmed, W.H.; Abdou, S. Two-Phase Flow Mass Transfer Analysis of Airlift Pump for Aquaculture Applications. Fluids 2021, 6, 226. https://doi.org/ 10.3390 /fluids 6060226

Academic Editors: Goodarz Ahmadi and Mehrdad Massoudi

Received: 29 April 2021

Accepted: 11 June 2021

Published: 16 June 2021

Publisher's Note: MDPI stays neutral with regard to jurisdictional claims in published maps and institutional affiliations.

Copyright: (c) 2021 by the authors. Licensee MDPI, Basel, Switzerland. This article is an open access article distributed under the terms and conditions of the Creative Commons Attribution (CC BY) license (https:/ / creativecommons.org/licenses/by/ $4.0 /)$.

\begin{abstract}
Airlift pumps can be used in the aquaculture industry to provide aeration while concurrently moving water utilizing the dynamics of two-phase flow in the pump riser. The oxygen mass transfer that occurs from the injected compressed air to the water in the aquaculture systems can be experimentally investigated to determine the pump aeration capabilities. The objective of this study is to evaluate the effects of various airflow rates as well as the injection methods on the oxygen transfer rate within a dual injector airlift pump system. Experiments were conducted using an airlift pump connected to a vertical pump riser within a recirculating system. Both two-phase flow patterns and the void fraction measurements were used to evaluate the dissolved oxygen mass transfer mechanism through the airlift pump. A dissolved oxygen (DO) sensor was used to determine the DO levels within the airlift pumping system at different operating conditions required by the pump. Flow visualization imaging and particle image velocimetry (PIV) measurements were performed in order to better understand the effects of the two-phase flow patterns on the aeration performance. It was found that the radial injection method reached the saturation point faster at lower airflow rates, whereas the axial method performed better as the airflow rates were increased. The standard oxygen transfer rate (SOTR) and standard aeration efficiency (SAE) were calculated and were found to strongly depend on the injection method as well as the two-phase flow patterns in the pump riser.
\end{abstract}

Keywords: two-phase flow; mass transfer; aeration; flow patterns; airlift pump

\section{Introduction}

Within the aquaculture industry, aeration and water circulation are among the most essential needs to maintain the proper dynamics of a lake [1]. Both of these processes assist in sustaining and prolonging the life of a body of water, while simultaneously improving the water quality, as well as the health and the production capacity of the farmed aquatic animal [2]. Water circulation is typically used to keep the water temperature consistent, reduce stratification, increase nutrient solubility, and reduce the buildup of organic substances at the bottom of the tank [3]. In contrast, aeration, which is the addition of oxygen into the water, is used to support the aquatic life within the system by providing adequate aerobic conditions [1]. Airlift pumps are proven to be effective systems within this industry due to their ability to aerate and circulate water simultaneously.

An aerator's main function is to supply a pond with the proper concentration of dissolved oxygen in order to improve the energy efficiency of the oxygen transfer process [4]. A study testing the oxygen transfer within an airlift system concluded that if designed properly, an airlift pump can reach greater efficiencies for oxygen transfer than a diffused aeration system [5], eliminating the need for an added aeration device. Some important oxygen transfer parameters to evaluate the oxygenation occurring in the system are the standard oxygen transfer rate (SOTR) and the standard aeration efficiency (SAE). The SOTR can be defined as the mass of oxygen that can be added to the body of water per unit time at standard conditions $\left(20^{\circ} \mathrm{C}\right.$ water, $0 \mathrm{mg} / \mathrm{L}$ initial DO concentration and $1 \mathrm{~atm}$ 
pressure in clean water) [4]. The SAE on the other hand is the STOR per unit of power [4]. There are various aspects of an airlift pump that could affect the oxygen diffusion within the system. Conditions, such as bubble size, gas-liquid interfacial area and flow patterns, each influence the oxygen transfer rate and aeration efficiency in different ways. As bubble size is reduced, an increase in mass transfer is typically observed [6]. This is due to the available gas-liquid interfacial area [7]. The gas-liquid interfacial area can be described as the surface area available for the two phases to either coexist or interact with each other [8]. Therefore, compared to a few larger bubbles, a multitude of smaller bubbles increases the total surface area for oxygen to diffuse between the two phases. This was observed in a study conducted by Calderbank and Moo-Young [9], in which expressions for the mass transfer coefficient were determined for large gas bubbles, and the oxygen supply rate by aeration was consequently found to increase by expanding the gas-liquid contact area. A larger number of small bubbles can be achieved by using a sparger with a large number of holes [10].

Given that bubble sizing and their distribution directly affect the formation of flow patterns [11], it is therefore important to observe these factors in comparison to the mass transfer rate. The four common flow regimes categorized for two-phase flow in a vertical pipe are bubbly flow, slug flow, churn flow and annular flow. Bubbly flow consists of a multitude of small-sized bubbles that are less efficient in pumping water but increase mass transfer capabilities. Slug flow is the most efficient flow pattern in terms of pump performance due to its piston-like bubbles that allow more water to be lifted. Due to the larger bubble sizes in a slug flow pattern, the gas-liquid interfacial area is diminished compared to bubbly flow and therefore reduces its oxygen transfer rate. However, the increased turbulence at the tail end of each slug also helps increase the oxygen transfer rate. In the experiments conducted by Reinemann [12], this effect in the slug regime allowed the bubbly and slug flow to have similar gas transfer rates, and this allowed him to draw the conclusion that flow pattern did not have a significant effect on oxygen transfer. The chaotic nature of the churn flow pattern is an advantage as it decreases the mass transfer resistance between the liquid film on the bubbles' surface to the bulk of the liquid, which in turn increases mass transfer [13]. The last of the flow patterns is annular flow, which occurs when the velocity of gas increases to a point where it pushes the liquid into a film against the interior tube wall [14].

Another factor that has an influence on mass transfer within an airlift pump is the superficial gas velocity. Superficial gas velocity refers to the ratio of airflow rate to the cross-sectional area of the riser pipe [15]. As concluded in various studies, an increase in superficial gas velocity results in an increased gas-liquid mass transfer coefficient $[13,16,17]$. This is because with a higher airflow rate, gas hold up, which is the amount of gas within the column at a given time, increases and decreases the average bubble diameter which subsequently expands the gas-liquid interfacial area available for mass transfer to occur [13]. Furthermore, by increasing the airflow rate, the bubbles start to rise at a higher velocity which creates more turbulence in the system, also helping with mass transfer [13]. Similarly, a study conducted by Kumar and Vinod [18] examined the effect of the airflow rate on the mass transfer coefficient and found that the mass transfer coefficient increased as the airflow rates of the system were increased [18].

The airlift technology is so versatile that the system design is often manipulated to be used in a variety of different industry systems. There are a number of papers in the literature that distinctly focus on variations of the airlift design and how it could affect the mass transfer occurring inside the system. This could include the geometry of the pump itself, a change in the riser or bubble column or even a different setup of the system. In Siegel's study [19], the interrelationship of the three main components in an airlift reactor being the riser, the downcomer as well as the gas-liquid separator, were compared with the mass transfer in the reactor [19]. Twenty different reactor geometries were tested, and it was found that the gas-liquid separator plays an important role in the reactors' behavior and therefore should be highly considered in the design. Furthermore, it was determined 
that a correlation exists between the pneumatic power gas input per total dispersion volume, the riser superficial gas velocity for each condition tested and the overall mass transfer coefficient [19]. Another set of experiments conducted by Drandev et al. [20] explored the ratio of the cross-sectional area of the downcomer to the riser ( $\mathrm{Ad} / \mathrm{Ar}$ ) in airlift reactors and its effect on the oxygen mass transfer of the system. The airlift reactor used in this experimental setup changed the conventional reactor shape to a rectangular one. The results concluded that a rectangular-shaped reactor had better oxygen mass transfer characteristics at a cross sectional area ratio of 2.0 [20].

Another method of changing the airlift system design that could affect the oxygen transfer coefficients is by adjusting the riser pipe diameter or shape. In a study conducted by Pi et al. [21], the idea of a trumpet-shaped riser was investigated. This trumpet-shaped riser was placed inside an airlift reactor where it could act as a modified internal-loop reactor [21]. From the experiments performed, the volumetric oxygen transfer coefficient was greatly influenced by the ratio of riser height to the static fluid head above the spargers, the ratio of the area of the cross-section of the riser to the downcomer (Ar/Ad) and the superficial gas velocity within the riser [21]. This uniquely formed riser provided optimal conditions for fluid circulation which enhanced the efficiency of the oxygen transfer and an oxygen transfer rate of $(2.17 \pm 0.11) \times 10^{-5} \mathrm{~kg} \mathrm{~m}^{-3} \mathrm{~s}^{-1}$ was recorded with an oxygen mass transfer coefficient of $(27.88 \pm 1.12) \times 10^{-3} \mathrm{~s}^{-1}$ [21].

In the present study, a dual injector airlift pump designed by Ahmed and Badr [22] is examined to determine its aeration capabilities. The two different injection geometries (axial and radial) of the pump are experimentally evaluated at various airflow rates to obtain the standard oxygen transfer rate and the aeration efficiency. Observations of bubble size, flow pattern and flow behavior around a bubble are used to further validate findings through flow visualization imaging, and particle image velocimetry (PIV) measurements.

\section{Materials and Methods}

The experimental setup for an airlift pump that uses water and compressed air for the two-phase flow is depicted in Figure 1. This looped system pumps water into a supply tank from a $125 \mathrm{~L}$ reservoir tank using a sump pump. An adjacent tank allows the water to overflow, keeping the water level at a specified head. This setup is adjustable to allow for changes in the submergence ratio, also known as the water head, over the total length of the riser pipe $\left(\mathrm{H}_{\mathrm{S}} / \mathrm{L}\right)$. For the purpose of representing the most common operating conditions used at the aquaculture facilities, a submergence ratio of 0.7 was selected for all present tests. From the supply tank, the water enters an airlift pump that is connected to a $1.6 \mathrm{~m}$ riser pipe with an ID of $31.75 \mathrm{~mm}$, creating a lift height of $0.48 \mathrm{~m}$. Using compressed air, the airlift pumps the water in this pipe up to the delivery tank. At this point, any excess pressurized air is released into the atmosphere while the water is transported to a collecting tank. From there, flow rate measurements can be taken before the water is returned to the reservoir tank where the cycle can continue. The water used in the system was deionized water to ensure minimal contaminants and mineral deposits.

For the pneumatic portion of this setup, the supplied air is fed through a pressure regulator using a $6 \mathrm{~mm}$ hose. The airline is then split to account for the axial and the radial injection points, each of which is connected to a needle valve to control the flow rates. The air then passes through digital mass flow meters to regulate the airflow rate and collect temperature and pressure readings before injecting the air into the pump. For the dissolved oxygen testing, the water was purged of oxygen by injecting nitrogen into the reservoir tank. This was achieved using a nitrogen tank connected to a $6 \mathrm{~mm}$ hose that had a small $25 \mathrm{~mm}$ air stone attached at the end to help with diffusion. 


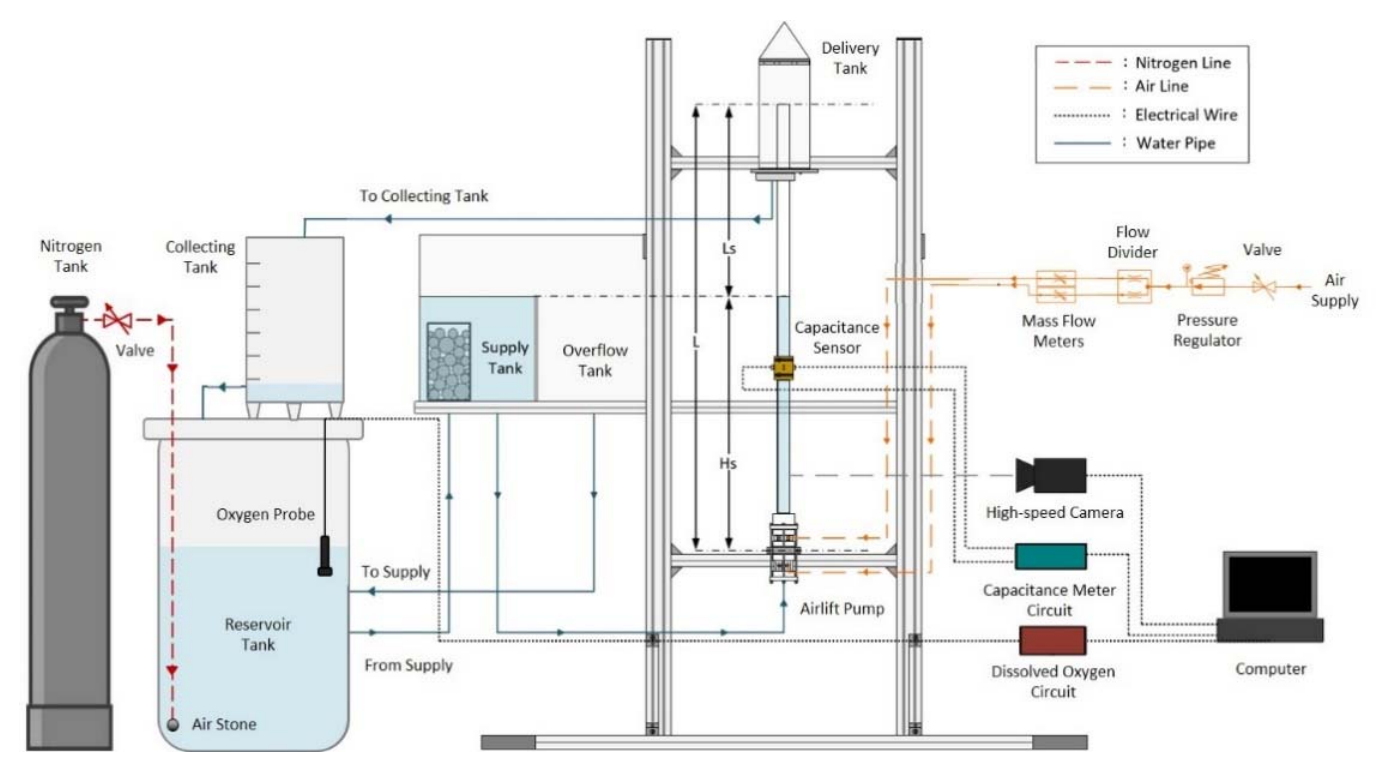

Figure 1. Schematic diagram of the experimental setup.

In order to perform a flow visualization analysis of the two-phase flow patterns occurring in the system, a high-speed camera setup was utilized. This setup required a light and a diffuser sheet to be placed behind the riser pipe in order to adequately capture the flow image. The recorded videos were then transferred onto the MiDAS computer software where the high-speed footage could be further analyzed.

Throughout the experiments, two mass flow meters ranging from 0-500 SLPM were used to monitor the airflow rates entering the system. Each of these mass flow meters has a reading error of $\pm 0.8 \%$ as well as an error of $\pm 0.2 \%$ of full scale. An uncertainty of $\pm 1.2 \%$ was therefore calculated for the air mass flow rate. The water mass flow rate was determined using a stopwatch with increments of 1 millisecond to record the time it took to fill the collection tank in increments of $1 \mathrm{~L}$. From this, the water mass flow rate uncertainty was calculated to be $\pm 3 \%$. The efficiency of the airlift pump was determined using Equation (1) and had a calculated uncertainty of $\pm 0.3 \%$. Additionally, the DO measurements were recorded using a DAQ system and a LabVIEW program that was designed to receive, record and analyze the collected data. Instantaneous DO measurements were collected at a sampling frequency of $1 \mathrm{kHz}$ over a period of 100 seconds in order to ensure that the received measurements are statistically adequate to present the variations in these measurements.

\subsection{Pump Design}

The $31.75 \mathrm{~mm}$ airlift pump being tested in this study is an optimized dual injector model designed by Ahmed and Badr [22] as shown in Figure 2. This design consists of two main geometries: axial and radial. The radial inlet consists of a perforated tube of the same inner diameter as the riser pipe. There are 180 holes evenly distributed radially along the circumference of this component, each hole measuring $1.7 \mathrm{~mm}$ in diameter. The purpose of the radial inlet is to create bubbles in the form of slugs, which allows for a larger surface area to raise the water. The axial injection geometry consists of a smaller diameter pipe within the pump that extends approximately $12 \mathrm{~mm}$ above the injection site. This design forces the injected air to hit the inner pipe, creating a shear force upwards along the wall. For the purpose of these experiments, the axial and the radial geometries were tested separately to compare their oxygen mass transfer rates. 

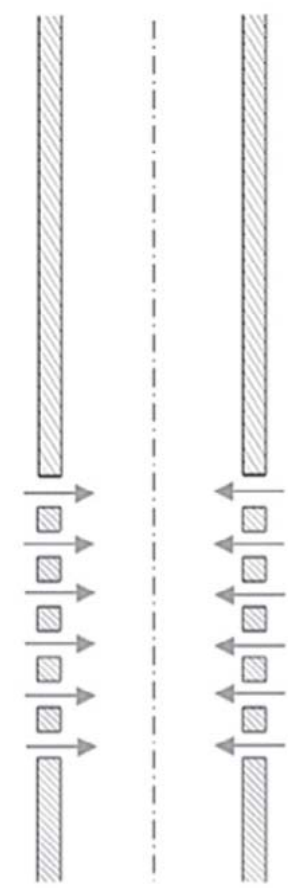

(1) Radial injector

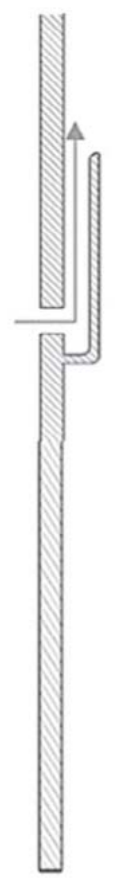

(2) Axial injector
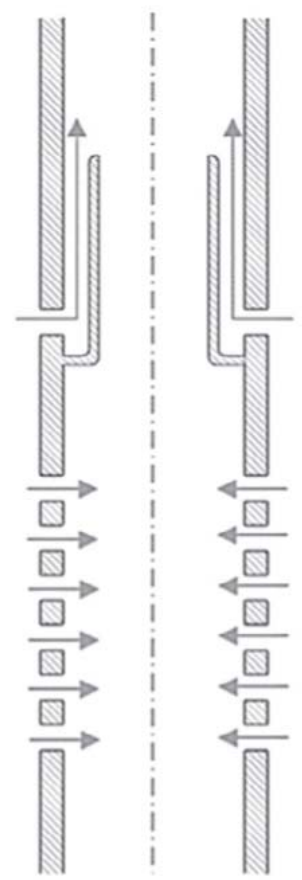

(3) Dual injector

Figure 2. Schematic of dual injector airlift pump [22].

In this study, the efficiency of the pump can be found using a modified definition of Nicklin's equation as follows [23]:

$$
\eta=\frac{\rho g Q_{L}\left(L-H_{S}\right)}{P_{a t m} Q_{G} \ln \left(\frac{P_{\text {in }}}{P_{\text {atm }}}\right)}
$$

In this equation, $Q_{L}$ is the water discharge and $Q_{G}$ is the volumetric flow rate of air, both measured in $\mathrm{m}^{3} / \mathrm{s}$. The pressures were recorded in Pascals where $P_{\text {in }}$ is the injection pressure of air and $P_{a t m}$ is the atmospheric pressure. The variables $\rho$ and $g$ are the water density $\left(\mathrm{kg} / \mathrm{m}^{3}\right)$ and the gravitational acceleration $\left(\mathrm{m} / \mathrm{s}^{2}\right)$, and $L$ and $H_{s}$ measured in meters are the length of the riser pipe and the static head respectively. These variables are also defined visually in Figure 1.

\subsection{Capacitance Sensor}

The void fraction is defined as the percentage of the riser pipe that is occupied by air. A capacitance sensor uniquely designed for this experimental setup that was developed by Elsaftawy et al. [24] was used to measure the void fraction. This design is comprised of three main components: two capacitance sensors, a meter circuit, and a LabVIEW interface [24]. The LabVIEW program was designed to receive, record and graph the capacitance signal as well as find the average void fraction. When performing the experiments, the void fraction data were collected at a sampling frequency of $2.5 \mathrm{kHz}$ over a period of 100 seconds. The uncertainty of the void fraction calculated using static calibration was found to be $\pm 6 \%$.

\subsection{Oxygen Probe and Circuit}

To measure the dissolved oxygen in these experiments, a galvanized dissolved oxygen probe was used. The dissolved oxygen probe was fixed in the reservoir tank as this allows time for the pumped water to fully mix back into the system before readings are taken. Therefore, this provides a better representation of the time it would take the entire system to reach saturation. The probe works by allowing oxygen molecules to diffuse through a membrane where they can be reduced when they reach the cathode, producing 
a small voltage that increases as the oxygen increases. A circuit was designed using an embedded dissolved oxygen circuit in order to process the data recorded by the probe and record the findings through the LABVIEW interface. As stated on their data specification sheets, the uncertainty of both the probe and the embedded dissolved oxygen circuit was $\pm 0.05 \mathrm{mg} / \mathrm{L}[25,26]$.

\subsection{PIV System}

A planar PIV system was used to measure the water velocity field in a vertical plane downstream of the air injector. Figure 3 illustrates the setup configuration of the PIV system. The velocity field was measured in a vertical plane containing the pipe centerline. The plane was illuminated by a light sheet obtained from a set of optics and a laser source. Polymer Seeding Particles (PSP) were seeded into the supply tank and present within the liquid in the pipe. Each round seeding particle has a diameter of $20 \mu \mathrm{m}$ and is white in color. The airlift loop is left to run for a sufficient period of time to ensure homogeneous distribution of the seeding particles within the liquid. A high-speed camera along with several lenses and filters are required for optical recording to capture successive images of the laser sheet that illuminates the flow section under investigation. The purpose of the camera is to detect the locations of seed particles in the flow field illuminated by the laser light sheet. The utilized camera is the SpeedSense Lab 320 provided by DentecDynamics. This high-speed camera can reach a frame rate of 1380 frames per second with a sensor resolution of up to $1920 \times 1200$ pixels $^{2}$. For each run, the camera focus and aperture are adjusted such that the particles are observed clearly within the flow with no distortions in order to ensure high image quality. A synchronizer connected to the laser, the camera and the host computer is used to control the timing of the laser pulses and the captured images.

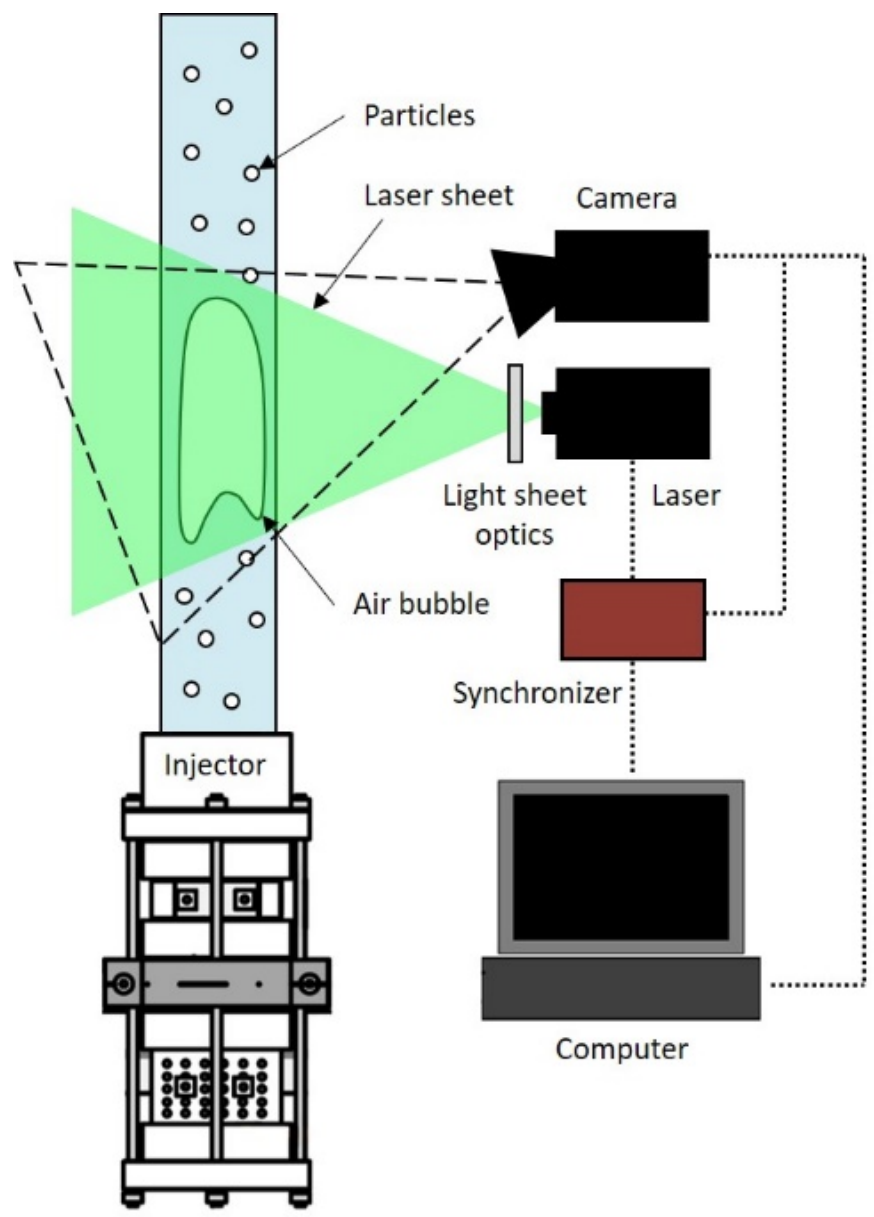

Figure 3. Schematic diagram of PIV system setup. 
To operate the PIV setup, compressed air is injected with an extremely low flow rate through the radial air injector only, in order to observe and measure the behavior of the flow field. This is achieved by allowing a single slug bubble to be injected by opening the airflow control valve for a short burst of time. Following the air injection, air bubbles will start to rise, and the seeded particles will pass by the illuminated laser sheet. The camera is positioned perpendicularly to the laser sheet into the page while the laser sheet captures the particles passing through a vertical plane in the middle of the pipe. This allows the camera to capture images separated by a constant time interval of $\Delta t$. The captured images can then be stored and processed, and the liquid velocity vectors can be determined by using the cross-correlation method. During experimentation, several factors can be controlled and adjusted in order to best track the interrogation areas and observe clear particles. These factors include the exposure time, triggering rate, image resolution, interrogation area size, laser sheet intensity, camera position, seeding particles concentration, and laser sheet thickness. It is important to mention that at low airflow rates, the shape of the bubbles and the rate at which they propagate through the liquid change.

\section{Results}

\subsection{Continuous Flow Experiments}

The following continuous flow experiments were performed to find the water flow rate, the void fraction, and the efficiency of the axial and the radial injection methods for the airlift pump. These data could then be compared to the mass transfer experiments to validate the results. Experiments were conducted for both the axial and the radial injections, at airflow rates of 7, 10, 15, 20 and $30 \mathrm{LPM}$ (or 0.57, 0.84, 1.33, 1.93 and $3.79 \mathrm{~kg} / \mathrm{h}$ ). From the measured water flow rates, a characteristic curve was created to compare the performance of each injection method, as seen in Figure 4a. The performance curves show an increase in the water flow rate as the airflow is increased, and that the radial method has a slightly better performance than the axial injection. This can be related to the higher air momentum created from the axial geometry, causing the air to penetrate the liquid rather than lift it. This in turn reduces its buoyancy effect. As depicted in Figure $4 \mathrm{~b}$, the efficiency of both methods was calculated and compared from these performance curves. The efficiency of the pump is generally greater at lower airflow rates; it decreases drastically as the airflow rates are increased. Both the axial and the radial curves reached their highest efficiency point at airflow rates of 10 LPM. Despite having a slightly lower performance rate, the axial injection method achieved a much higher efficiency than the radial method. The void fraction of each airflow rate can be seen in Figure 4c. As expected, the void fraction increased as the airflow rates were increased for both the axial and the radial injections; however, the radial method showed a less clearly defined linear trend than the axial one demonstrated. This can be attributed to the flow pattern occurring at the placement of the capacitance sensor. At 15 LPM, the radial injection showed a more chaotic churn flow where a constant air pocket was observed to develop in the measurement region of the sensor. This can explain why the void fraction showed a more sudden increase compared with its surrounding flow rates in Figure 4c. At 30 LPM, the flow regime starts to verge on annular flow which also accounts for the increased void fraction at that point. Overall, when taking the $6 \%$ uncertainty into account, the axial and radial void fraction results do not vary greatly between each other. Both the axial and the radial result specifications are summarized in Tables 1 and 2 below. 


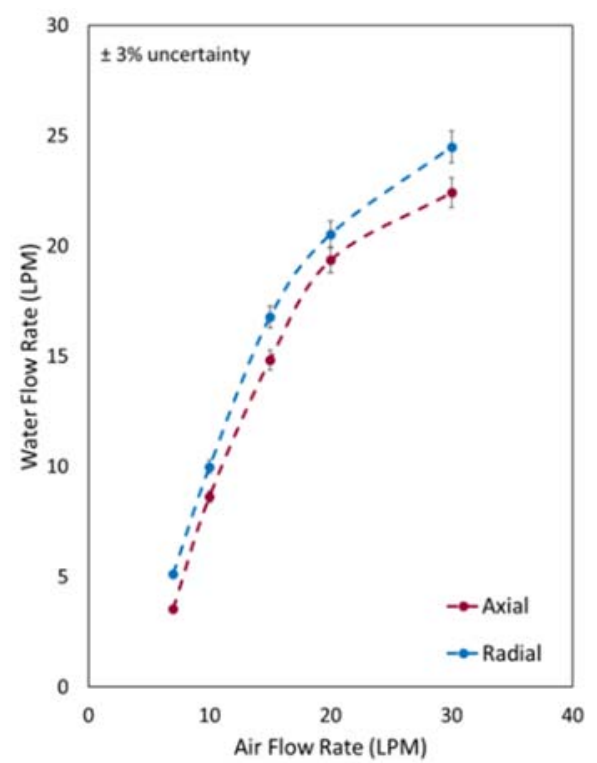

(a) Water Flow Rate

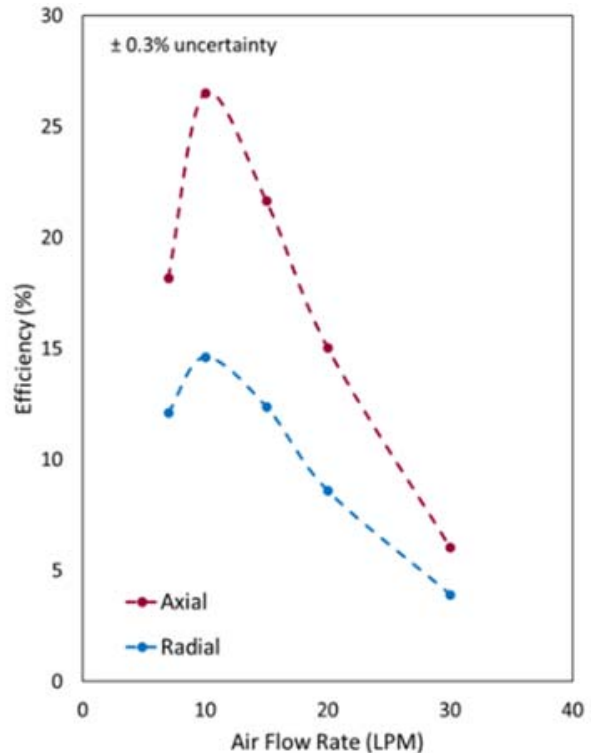

(b) Efficiency

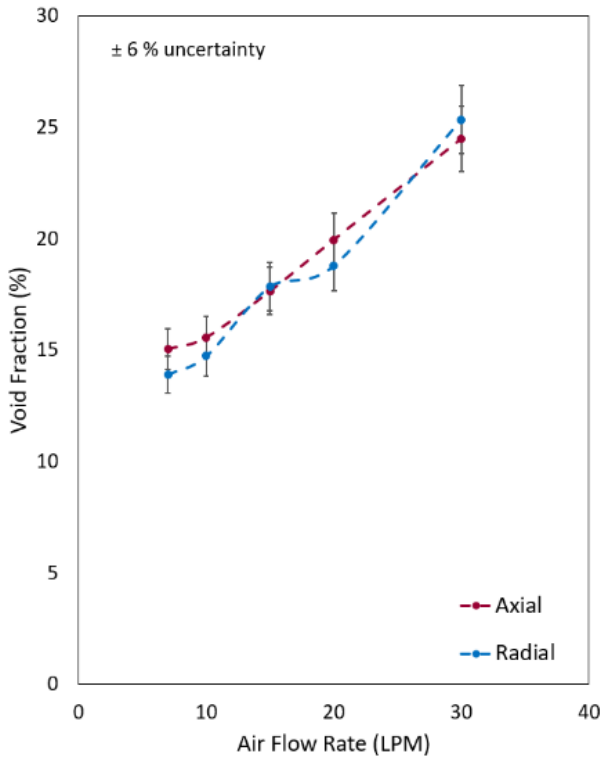

(c) Void Fraction

Figure 4. Water flow rate, efficiency and void fraction graphs for the axial and the radial injections.

Table 1. Axial result specifications.

\begin{tabular}{cccc}
\hline Air Flow Rate (LPM) & Water Flow Rate (LPM) & Void Fraction (\%) & Efficiency (\%) \\
\hline 7 & 3.55 & 15.05 & 18.19 \\
15 & 14.83 & 17.66 & 21.65 \\
30 & 22.42 & 24.49 & 6.04 \\
\hline
\end{tabular}

Table 2. Radial result specifications.

\begin{tabular}{cccc}
\hline Air Flow Rate (LPM) & Water Flow Rate (LPM) & Void Fraction (\%) & Efficiency (\%) \\
\hline 7 & 5.13 & 13.92 & 12.11 \\
15 & 16.79 & 17.87 & 12.39 \\
30 & 24.49 & 25.36 & 3.93 \\
\hline
\end{tabular}




\subsection{Mass Transfer Experiments}

For the oxygen mass transfer experiments, three flow rates were tested to cover the minimum to the maximum flow range available for the individual injection methods; therefore, the airflow rates tested were 7, 15 and 30 LPM. Before each trial, the water was purged of oxygen by injecting nitrogen until the oxygen levels reached below $1 \mathrm{mg} / \mathrm{L}$. Once this was performed, the airlift system was turned on and dissolved oxygen (DO) readings were taken until the saturation point was reached. The water temperature was recorded to be $24^{\circ} \mathrm{C}$, which has an $\mathrm{O}_{2}$ saturation of $8.4 \mathrm{mg} / \mathrm{L}$ [27].

In Figure 5, the axial and the radial DO curves are compared using airflow rates. At the lowest flow rate of 7 LPM, a flow regime between bubbly and slug flow occurs. When examining Figure 5a at 7 LPM, it is evident that the radial injection reached the saturation point much quicker than the axial one. This is because, at this lower flow rate, the radial geometry produces smaller bubbles, which increase the available surface area in which oxygen mass transfer can occur. This can be observed in Figure 6a, in which the radial flow images depict a greater density of small bubbles. In comparison, the axial flow had more air contributing towards the formation of a larger slug bubble in the center. Furthermore, when visually inspected, the radial method appeared to have a slower flow during testing. This is due to the geometry of the injection point, which creates less momentum in the direction of the flow. This also contributes towards the increased DO rate since there is more time for mass transfer to occur when the flow is slowed down.

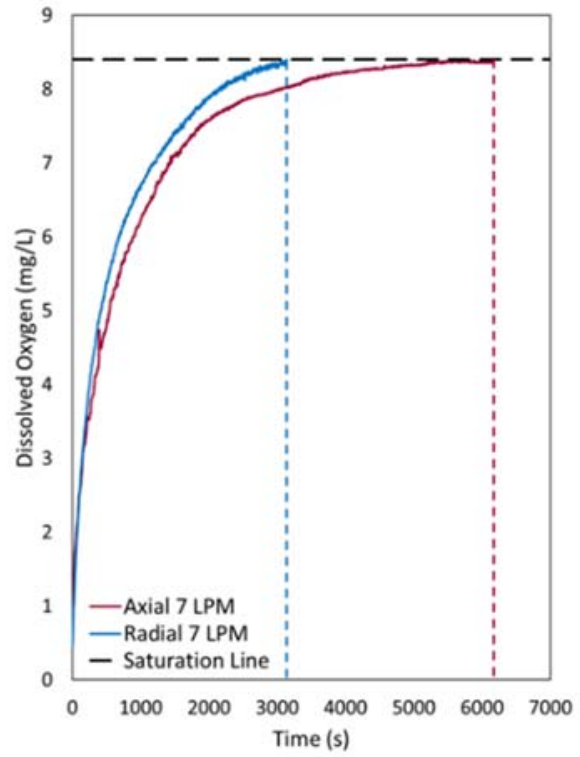

(a) 7 LPM

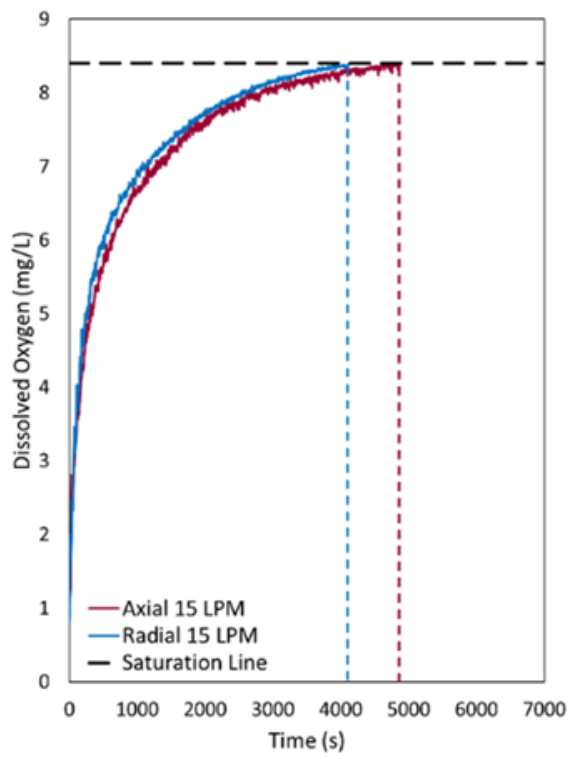

(b) 15 LPM

Figure 5. Cont. 


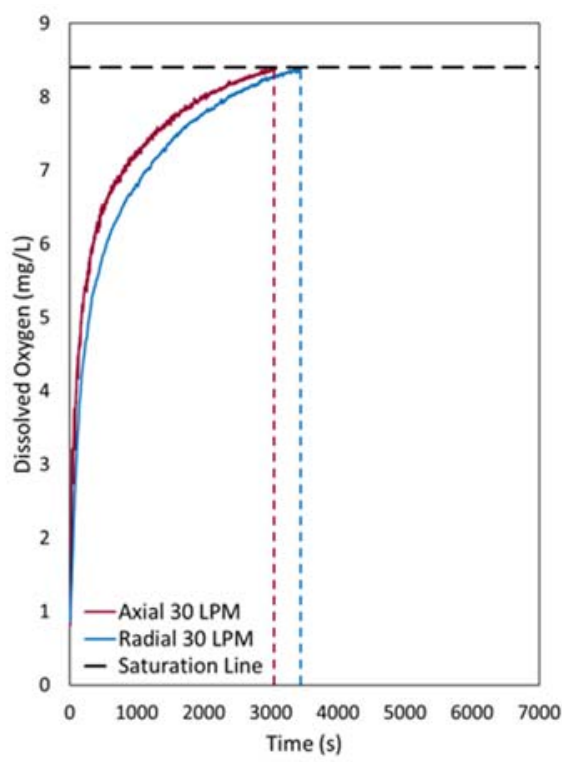

(c) $30 \mathrm{LPM}$

Figure 5. Dissolved oxygen curves at airflow rates of 7, 15 and 30 LPM comparing axial and radial injections.

(a)

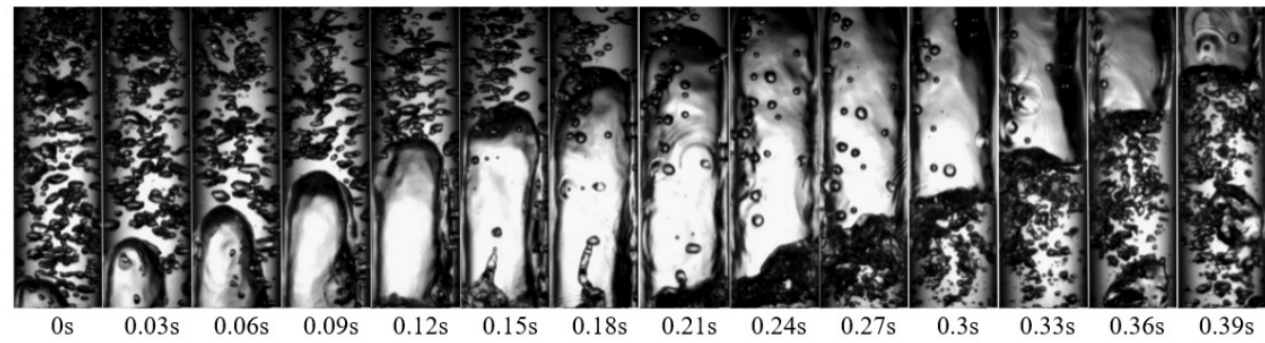

(b)

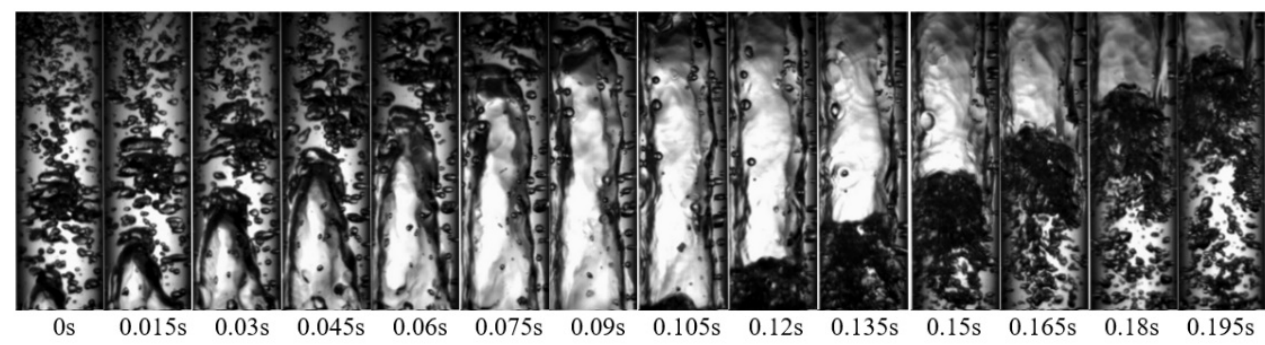

(c)

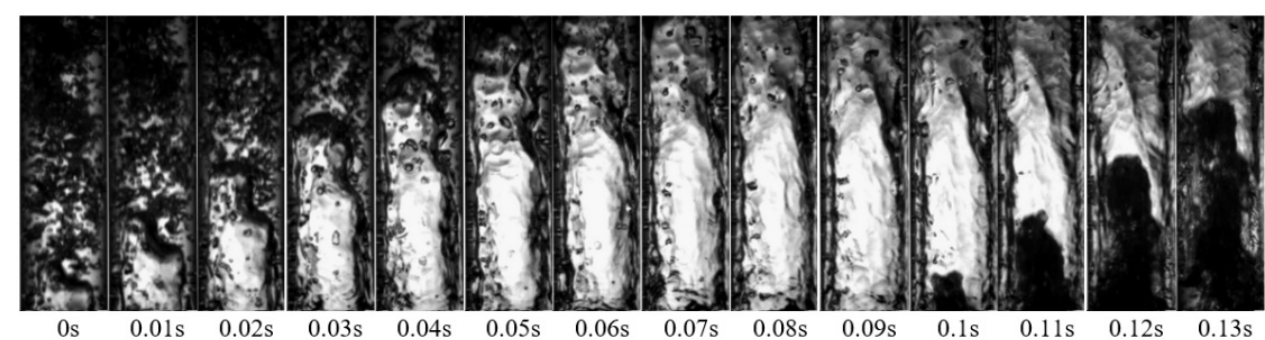

Figure 6. Flow visualization images at: (a) 7, (b) 15 and (c) 30 LPM for radial injection.

As the airflow rate is increased, the smaller bubbles start to coalesce and the flow pattern shifts to a more chaotic form, veering towards churn flow. This shift can be seen at $15 \mathrm{LPM}$ in Figures $6 \mathrm{~b}$ and $7 \mathrm{~b}$ at which point both the axial and the radial images show less defined, more distorted slug bubbles. It is important to note that at this airflow rate, the flow patterns between the axial and the radial injection methods become more similar, as is reflected in the DO results seen in Figure 5b. Although the radial method again 
outperformed the axial one by meeting the saturation point earlier, the time difference became less significant due to the similarity in the flow regimes.

(a)

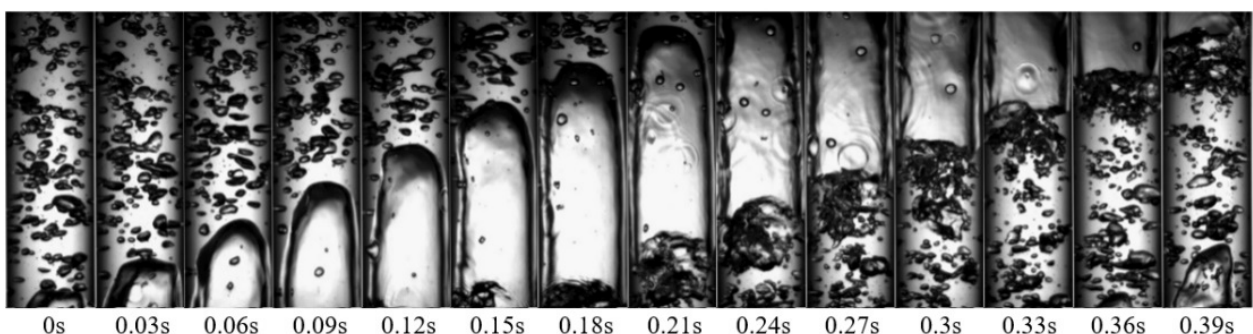

(b)

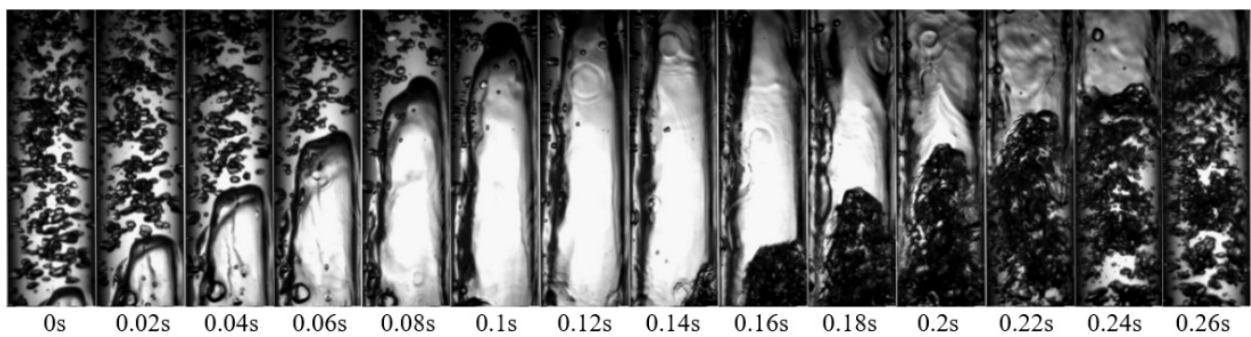

(c)

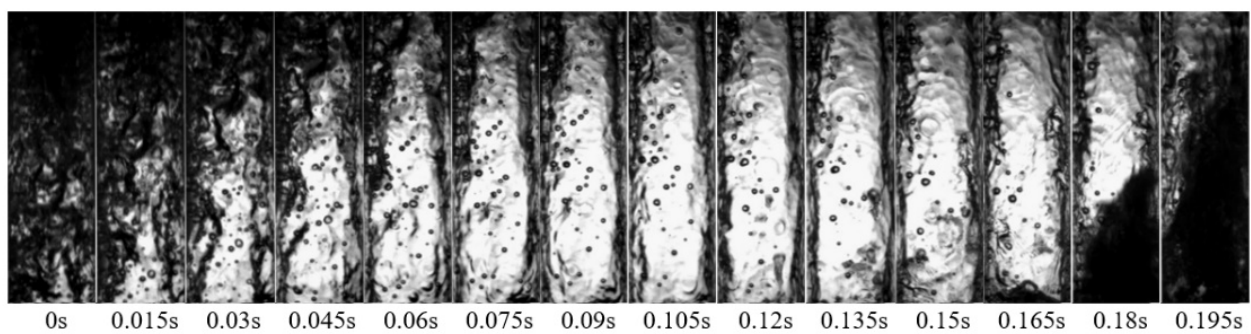

Figure 7. Flow visualization images at: (a) 7, (b) 15 and (c) 30 LPM for axial injection.

At the highest airflow rate, the flow became a mix of churn and annular flows. Unlike in the other flow rates, the axial method reached saturation before the radial one at 30 LPM (Figure 5c). During testing, it was observed that the axial method involved more mixing between the two phases due to a reversal in the flow at different points along the length of the pipe. The increased amount of reverse flow can be attributed to the design of the axial injection since the flow is directed upwards, increasing the momentum along the walls of the pipe. This can also explain why the axial injection appeared to be slightly slower than the radial one during testing. Both these phenomena contribute to the greater oxygen mass transfer rate that was recorded. When examining both the axial and the radial flow regimes in Figures $6 c$ and $7 c$, the images appear to be far more chaotic but similar in nature to each other. This accounts for the even smaller time difference between the axial and radial DO curves. Moreover, the axial flow also appeared to have more visible small bubbles. These could be an effect of the mixing which occurs, thus increasing the available surface area for mass transfer.

\subsection{Flow Field PIV Experiments}

In addition to the flow visualization images, the local velocity of the liquid phase is analyzed using the PIV system. The main objective of these local velocity profiles is to qualitatively identify the high-velocity region in the flow field that effluence the slip ratio between the gas and liquid phases and consequently the interfacial phenomena responsible for the higher mass transfer rates. These data can be useful in understanding the effects of turbulence on the oxygen mass transfer capabilities of the airlift pumping system. This was achieved by examining the flow field in the vicinity of a single slug bubble. For these purposes, the results in this section can be divided into two main regions: the regions downstream and upstream of the bubble. 


\subsubsection{Downstream Flow Field}

Upon the injection of the bubble and before the bubble reaches the area of measurement, the water in the test section is displaced upward as a result of the occupying bubble located upstream of the area of measurement. Figure 8 shows the average velocity profile and the standard deviation downstream of the slug bubble for interrogation area sizes of $8 \times 8$ pixel $^{2}, 16 \times 16$ pixel $^{2}$, and $32 \times 32$ pixel $^{2}$. X represents the radial direction with a reference position of 0 at the left end. The figure shows a uniform velocity for most of the radial dimensions of the pipe with a sharp velocity gradient near the wall due to the no-slip condition. Velocity distributions for interrogation areas of $16 \times 16$ pixel $^{2}$ and $32 \times 32$ pixel $^{2}$ show a perfect match especially in the core region with small differences near the wall. On the other hand, interrogation size of $8 \times 8$ pixel $^{2}$ seems to have a slightly lower velocity in the core region. This difference can be attributed to low particle density for each interrogation window in the case of the $8 \times 8$ pixel $^{2}$. Since the shown velocity profiles are averaged over a sufficient period of time before the introduction of a single slug bubble into the area of measurement, the standard deviation is also reported in Figure 8. For all interrogation area sizes considered, the maximum value of the standard deviation reported was about $0.0032 \mathrm{~m} / \mathrm{s}$ which is an acceptable low value. This indicates that there is a small variation of velocities within the time range considered for averaging.

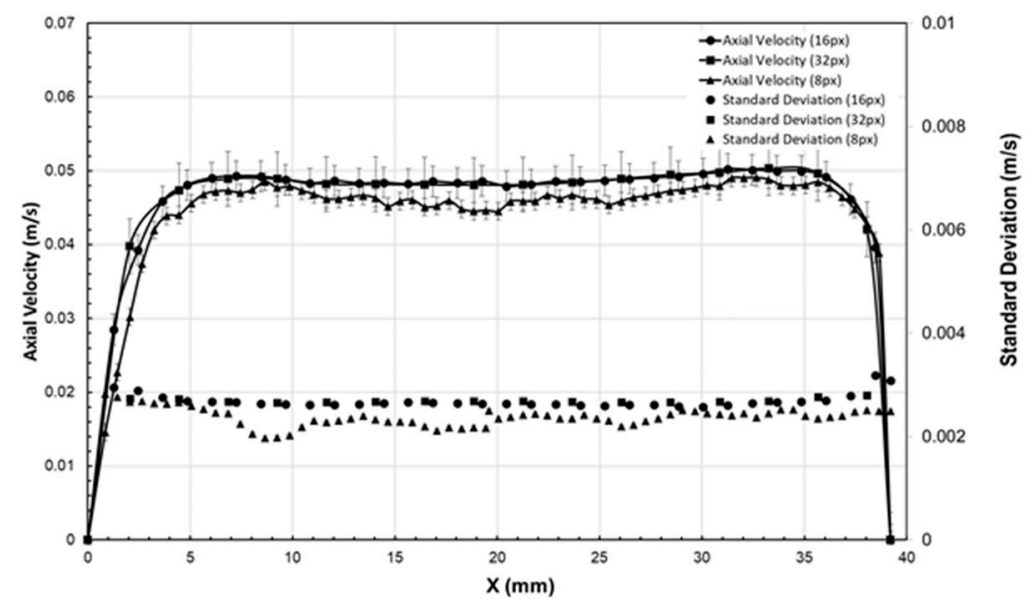

Figure 8. Average velocity and standard deviation distribution far downstream the slug bubble for different interrogation area sizes.

\subsubsection{Upstream Flow Field}

As the slug bubble is introduced to the measurement area, a different flow behavior is observed upstream. Figure 9 depicts the velocity vectors near the slug bubble's front end as well as the velocity profile at the indicated radial line. As the bubble approaches the test section, the liquid near the wall starts reversing direction and flowing downward with a high velocity. On the other hand, the liquid in the core near the bubble surface is displaced by the upward bubble and goes towards the pipe wall. The liquid film flows downward with such a high velocity that it is not captured at $100 \mathrm{~Hz}$. The velocity profile at the indicated section shows a low positive axial velocity downstream from the slug bubble, while negative velocity near the wall implies the downward velocity of the liquid film. 


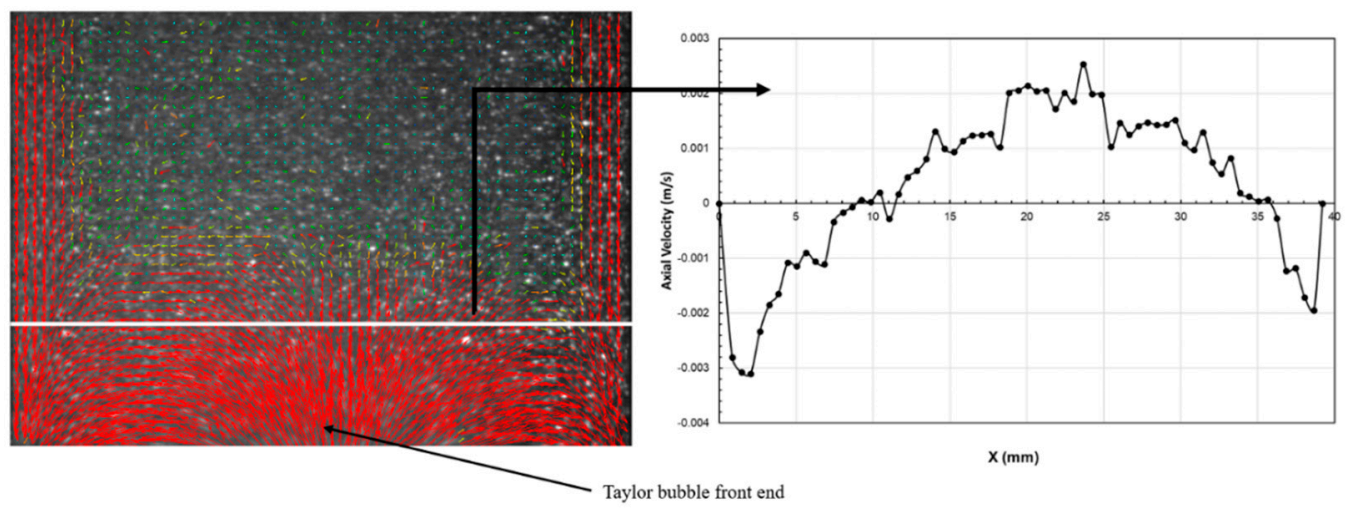

Figure 9. Velocity vectors and profile in the vicinity of the slug bubble front end.

Figure 10 shows the velocity vectors during the slug bubble propagation through the area of measurement. The figure shows invalid vectors produced by the software on the slug bubble which are not considered. Moreover, the liquid film is flowing downward with a very high velocity which is not captured by the software at $100 \mathrm{~Hz}$ and requires a higher triggering rate. A higher triggering rate is constrained by the lower exposure time of the camera. Reducing the exposure time results in unclear particles. Hence, higher laser sheet intensity is needed to capture the liquid films' fast motion. Irrespective of the triggering rate selected, the region of the liquid film to the left of the slug bubble remains unseen. This is because the laser sheet is reflected by the bubble before reaching this region.

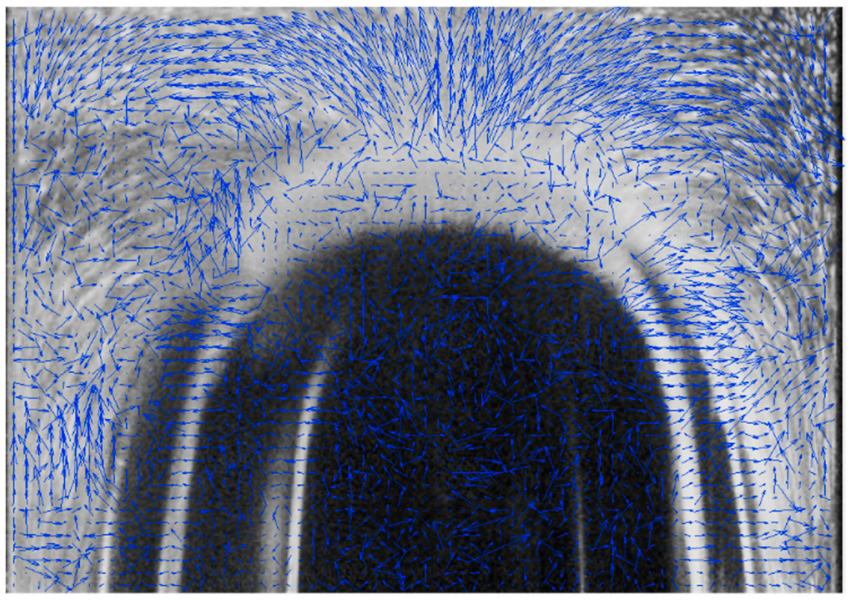

Figure 10. Liquid velocity vectors around the nose of the slug bubble.

Near the bubble's front end, the liquid was displaced upward and towards the wall into a falling liquid film. The liquid film flows downward with a high velocity, increasing agitation. Upstream of the slug bubble, a dense region of small deformable bubbles exists. Some of these bubbles were originally parts of the slug bubble, while others merged with the slug as time advanced. In a bubbly flow regime, deformable bubbles were found to induce lots of vortices in the stagnant water. The chaotic motion of the deformable bubbles can be a source of pseudo turbulence [28]. This bubble-induced agitation commonly occurs when its surroundings are also turbulent, creating a more complex agitation when combined [28] which in turn increases mass transfer capabilities. 


\subsection{Aeration Performance}

After completing the mass transfer testing, the oxygen transfer rate was calculated using the following correlations as described by Loyless and Malone [29]. To begin, the transfer coefficient $\left(k_{L} a_{T}\right)$ can be found using Equation (2):

$$
-\ln \left(\frac{C_{s}-C_{t}}{C_{s}-C_{o}}\right)=k_{L} a_{T} \times t
$$

where $t$ is the time it took in seconds for the oxygen levels to reach the final concentration $\left(C_{t}\right)$ from the initial concentration $\left(C_{o}\right)$. In the study conducted by Loyless and Malone [29], it was stated that the results should be taken from above $20 \%$ and below $90 \%$ of the saturation concentration $\left(C_{s}\right)$. This was intended to exclude any results that may include measurement errors as the curve approaches the saturation point. Since the saturation concentration was set at $8.4 \mathrm{mg} / \mathrm{L}$ at the recorded temperature of $24.0^{\circ} \mathrm{C}$, the initial and final concentrations are 1.68 and $7.56 \mathrm{mg} / \mathrm{L}$. To find the transfer coefficient at the standard temperature of $20{ }^{\circ} \mathrm{C}$, Equation (3) was used to calculate $k_{L} a_{20}$ :

$$
k_{L} a_{T}=k_{L} a_{20} \times \theta^{(T-20)}
$$

where $T$ represents the experimental temperature, which is $24.0^{\circ} \mathrm{C}$ in this case, and $\theta$ represents an Arrhenius type relationship where $\theta$ is set to equal 1.024 [29]. With this, the standard oxygen transfer rate (SOTR) can be calculated in $\mathrm{kg}$ of $\mathrm{O}_{2} / \mathrm{h}$ using Equation (4):

$$
S O T R=k_{L} a_{20} \times C_{s, 20} \times V \times 3600 \times 10^{-6}
$$

The saturation concentration at a temperature of $20{ }^{\circ} \mathrm{C}\left(C_{s, 20}\right)$ is $9.07 \mathrm{mg} / \mathrm{L}$, where $V$ represents the volume in liters being oxygenated in the system, and a conversion factor is used to change seconds to hours and milligrams to kilograms. To find the standard aeration efficiency of the experiments, the power of injection first needs to be calculated using Equation (5):

$$
\text { Power }=\frac{\rho \times g \times H_{s} \times Q_{G}}{1000}
$$

The power equation is derived using $\rho$ as the water density in $\mathrm{kg} / \mathrm{m}^{3}, g$ as the acceleration due to gravity in $\mathrm{m} / \mathrm{s}^{2}, H_{s}$ as the static head at a 0.7 submergence in meters and the airflow rates $\left(Q_{G}\right)$ in $\mathrm{m}^{3} / \mathrm{s}$, all divided by 1000 to convert from $\mathrm{W}$ to $\mathrm{kW}$. After finding both the SOTR and the power, the aeration efficiency can be calculated in $\mathrm{kg}$ of $\mathrm{O}_{2} / \mathrm{kWh}$ using Equation (6). Using the equations above, the SOTR and the SAE results are calculated and graphed in Figures 11 and 12.

$$
S A E=\frac{\text { SOTR }}{\text { Power }}
$$

For the SOTR of the axial injection, the oxygen transfer rate shows an increase as the airflow rate was increased. In comparison, the radial injection showed more of a decrease, which was also reflected in the DO graphs. The radial test also shows a smaller change between each flow rate compared to the axial one. The SAE trend lines for both the axial and the radial tests depict a decreasing efficiency as the flow rates are increased. Furthermore, the efficiency directly correlates with the dissolved oxygen transfer rates depicted in Figure 5 where radial showed to be more efficient at 7 and 15 LPM while axial was more efficient at 30 LPM. These collective results are not definitive; however, they do suggest that the axial injection method may be more suitable for aeration at higher flow rates, while the radial one may be better suited for lower airflow rates. 


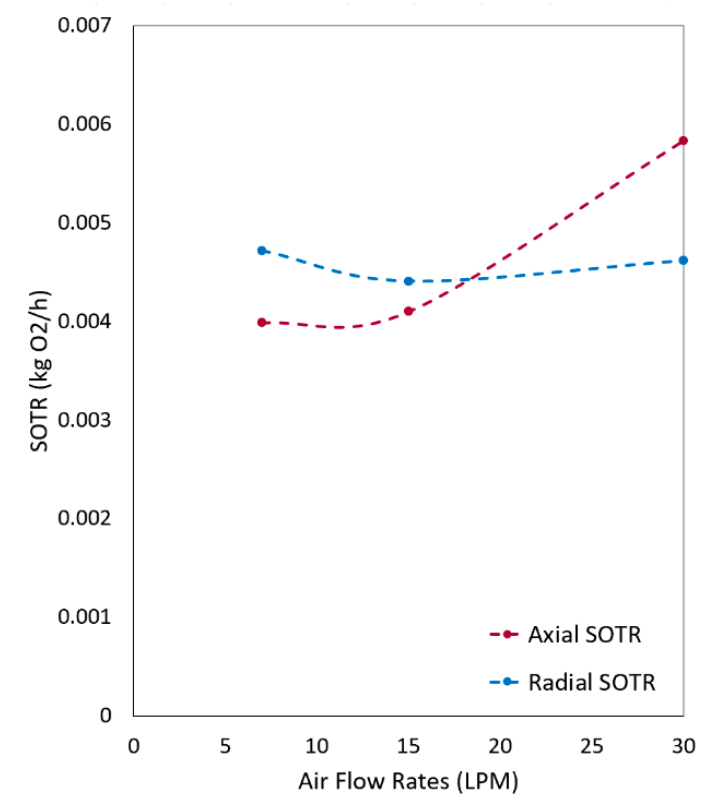

Figure 11. SOTR for axial and radial tests.

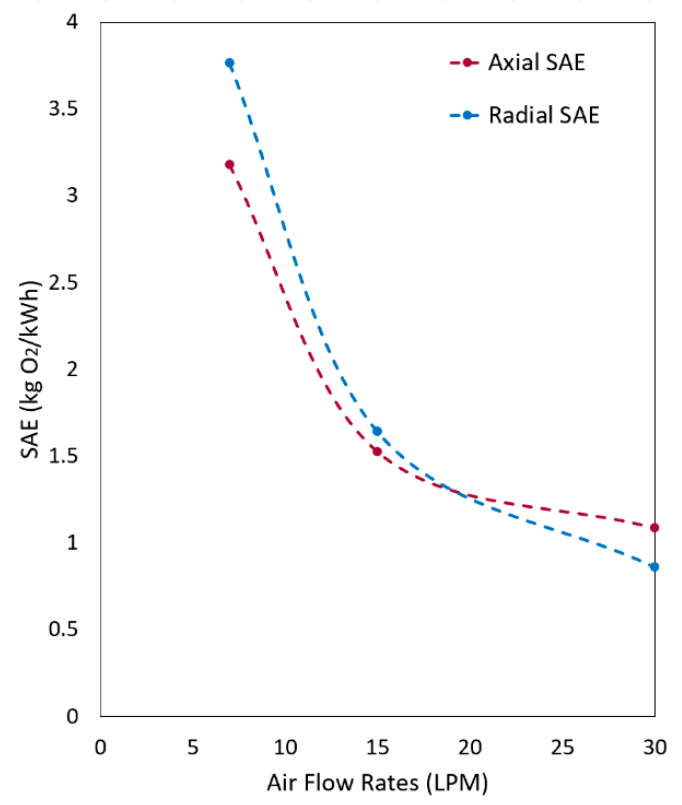

Figure 12. SAE for axial and radial tests.

\section{Conclusions}

In this paper, two different injection methods for an airlift pump were tested at various airflow rates to determine their oxygen transfer rates and aeration efficiencies. From the collected data, it was determined that the radial injection method might be better for lower airflow rates, while the axial injection was more effective at higher airflow rates, given the higher efficiency and faster time required to reach the saturation point. The flow imaging supported the findings in that the radial geometry, which was designed to help with aeration, showed an increased number of small bubbles, which in turn increased the mass transfer. In comparison, the axial method, which was designed to increase the lift, showed more defined slug bubbles. In future work, further experimentation could be carried out to record the dissolved oxygen at different points in the system. As well, an in-depth void fraction analysis could be performed to gain a wider understanding of the aeration capabilities of this airlift pump system. 
Author Contributions: Conceptualization, W.H.A.; methodology, W.H.A. and R.A.; formal analysis, R.A. and M.M.H.; investigation, R.A. and M.M.H.; resources, W.H.A.; writing-original draft preparation, R.A. and M.M.H.; writing-review and editing, R.A., W.H.A. and S.A.; supervision, W.H.A. and S.A. All authors have read and agreed to the published version of the manuscript.

Funding: This research was funded by the Ontario Ministry of Agriculture and Rural Affairs (OMAFRA), grant number 030398. The funding received from Mitacs and FloNergia Inc. under the Accelerate Internship project No. 460878 is greatly appreciated. The work is also partially funded by the Barrett Foundation under grant No. 054344.

Acknowledgments: The authors would like to acknowledge the support received from the Ontario Ministry of Agriculture and Rural Affairs (OMAFRA) under the Ontario Agri-Food Innovation Alliance grant to carry out the present research. Also, the funding received from Mitacs and FloNergia Inc. under the Accelerated Internship program to complete this work is highly appreciated.

Conflicts of Interest: The authors declare no conflict of interest. The funders had no role in the design of the study, in the collection, analyses, or interpretation of data, in the writing of the manuscript, or in the decision to publish the results.

\section{References}

1. Rogers, G.L. Aeration and circulation for effective aquaculture pond management. Aquac. Eng. 1989, 8, 349-355. [CrossRef]

2. Szeliga, J. Testing and Modelling the Oxygenation Potential of a Novel Dual-Injection Airlift Pump for Aquaculture Applications. Master's Thesis, The University of Guelph, Guelph, ON, Canada, 2018.

3. Parker, N.C.; Suttle, M.A. Design of airlift pumps for water circulation and aeration in aquaculture. Aquac. Eng. 1987, 6, 97-110. [CrossRef]

4. Kumar, A.; Moulick, S.; Mal, B. Performance evaluation of propeller-aspirator-pump aerator. Aquac. Eng. 2010, 42, 70-74. [CrossRef]

5. Reinemann, D.; Timmons, M. Prediction of oxygen transfer and total dissolved gas pressure in airlift pumping. Aquac. Eng. 1989, 8, 29-46. [CrossRef]

6. Barrut, B.; Blancheton, J.-P.; Champagne, J.-Y.; Grasmick, A. Mass transfer efficiency of a vacuum airlift-Application to water recycling in aquaculture systems. Aquac. Eng. 2012, 46, 18-26. [CrossRef]

7. Gavrilescu, M.; Roman, R.; Sauciuc, A. Oxygen mass transfer in an airlift bioreactor using static mixers. Biotechnol. Biotechnol. Equip. 1992, 6, 60-64. [CrossRef]

8. Revankar, S.; Ishii, M. Theory and measurement of local interfacial area using a four sensor probe in two-phase flow. Int. J. Heat Mass Transf. 1993, 36, 2997-3007. [CrossRef]

9. Calderbank, P. The continuous phase heat and mass-transfer properties of dispersions. Chem. Eng. Sci. 1995, 50. [CrossRef]

10. Kumar, N.; Bansal, A.; Gupta, R. Shear rate and mass transfer coefficient in internal loop airlift reactors involving non-Newtonian fluids. Chem. Eng. Res. Des. 2018, 136, 315-323. [CrossRef]

11. Zheng, Z.; Chen, Y.; Zhan, X.; Gao, M.; Wang, Z. Mass transfer intensification in a novel airlift reactor assembly with helical sieve plates. Chem. Eng. J. 2018, 342, 61-70. [CrossRef]

12. Reinemann, D.J. A Theoretical and Experimental Study of Airlift Pumping and Aeration with Refrence to Aquacultural Applications. Ph.D. Thesis, Cornell University, Ithaca, NY, USA, 1987.

13. Yang, W.; Wang, J.; Wang, T.; Jin, Y. Experimental study on gas-liquid interfacial area and mass transfer coefficient in three-phase circulating fluidized beds. Chem. Eng. J. 2001, 84, 485-490. [CrossRef]

14. Kassab, S.Z.; Kandil, H.A.; Warda, H.A.; Ahmed, W.H. Air-lift pumps characteristics under two-phase flow conditions. Int. J. Heat Fluid Flow 2009, 30, 88-98. [CrossRef]

15. Catrawedarma, I.G.N.B.; Deendarlianto; Indarto. The performance of airlift pump for the solid particles lifting during the transportation of gas-liquid-solid three-phase flow: A comprehensive research review. Proc. Inst. Mech. Eng. Part E J. Process. Mech. Eng. 2020, 1-23. [CrossRef]

16. Lukić, N.L.; Šijački, I.M.; Kojić, P.S.; Popović, S.S.; Tekić, M.N.; Petrović, D.L. Enhanced mass transfer in a novel external-loop airlift reactor with self-agitated impellers. Biochem. Eng. J. 2017, 118, 53-63. [CrossRef]

17. Bun, S.; Chawaloesphonsiya, N.; Ham, P.; Wongwailikhit, K.; Chaiwiwatworakul, P.; Painmanakul, P. Experimental and empirical investigation of mass transfer enhancement in multi-scale modified airlift reactors. Multiscale Multidiscip. Model. Exp. Des. 2019, 3, 89-101. [CrossRef]

18. Kumar, R.N.; Vinod, A.V. Oxygen mass transfer in bubble column bioreactor. Period. Polytech. Chem. Eng. 2014, 58. [CrossRef]

19. Siegel, M.H.; Merchuk, J.C. Mass transfer in a rectangular air-lift reactor: Effects of geometry and gas recirculation. Biotechnol. Bioeng. 1988, 32, 1128-1137. [CrossRef]

20. Drandev, S.; Penev, K.I.; Karamanev, D. Study of the hydrodynamics and mass transfer in a rectangular air-lift bioreactor. Chem. Eng. Sci. 2016, 146, 180-188. [CrossRef] 
21. Pi, K.; Huang, L.; Li, Z.; Gao, L.; Gerson, A.R. Oxygen mass transfer characteristics in an internal-loop airlift reactor with preset trumpet-shaped riser. Asia Pac. J. Chem. Eng. 2014, 9, 834-844. [CrossRef]

22. Ahmed, W.; Aman, A.; Badr, H.; Al-Qutub, A. Air injection methods: The key to a better performance of airlift pumps. Exp. Therm. Fluid Sci. 2016, 70, 354-365. [CrossRef]

23. Nicklin, D. Two-phase bubble flow. Chem. Eng. Sci. 1962, 17, 693-702. [CrossRef]

24. Elsaftawy, A.; Potts, J.; Ahmed, W. Oscillation frequency LCLC-based sensor for characterizing two-phase flows in energy systems. IEEE Sens. J. 2018, 19, 65-77. [CrossRef]

25. Atlas Scientific LLC. Dissolved Oxygen Probe. 2019. Available online: https://atlas-scientific.com/files/l-do-probe.pdf (accessed on 1 June 2020)

26. Atlas Scientific LLC. EZO-DO: Embedded Dissolved Oxygen Circuit. 2020. Available online: https://atlas-scientific.com/files/ DO_EZO_Datasheet.pdf (accessed on 1 June 2020).

27. Maximum Dissolved Oxygen Concentration Saturation Table; Lake Stewards of Maine-Maine Volunteer Lake Monitoring Program. Available online: https:/ /lakestewardsofmaine.org/wp-content/uploads/2014/01/Maximum-Dissolved-OxygenConcentration-Saturation-Table.pdf (accessed on 1 June 2020).

28. Alméras, E.; Mathai, V.; Lohse, D.; Sun, C. Experimental investigation of the turbulence induced by a bubble swarm rising within incident turbulence. J. Fluid Mech. 2017, 825, 1091-1112. [CrossRef]

29. Loyless, J.; Malone, R.F. Evaluation of air-lift pump capabilities for water delivery, aeration, and degasification for application to recirculating aquaculture systems. Aquac. Eng. 1998, 18, 117-133. [CrossRef] 